\title{
O círculo hermenêutico e a distinção entre ciências humanas e ciências naturais
}

\section{The hermeneutic circle and the distinction between the humanities and natural sciences}

Prof. Dr. Rui Sampaio da Silva

Universidade dos Açores [Pt]

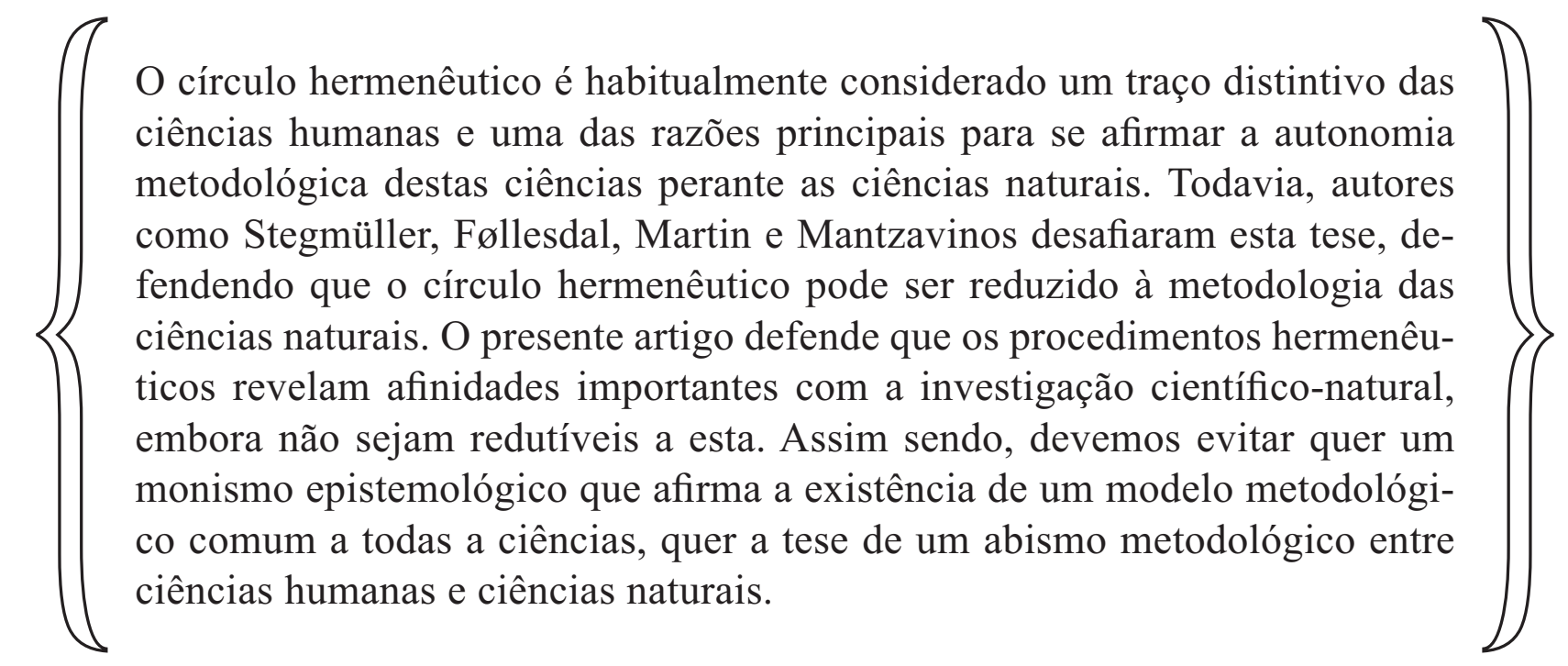

PALAVRAS-CHAVE

hermenêutica; interpretação; ciência;

teoria; observação

The hermeneutic circle is usually considered a distinctive trait of the human sciences and one of the main reasons to affirm the methodological autonomy of these science with regard to the natural sciences. However, authors like Stegmüller, Føllesdal, Martin and Mantzavinos have challenged this thesis, arguing that the hermeneutic circle can be reduced to the methodology of the natural sciences. The present article claims that the hermeneutic procedures have important affinities with the natural-scientific research, although they cannot be reduced to it. One should, therefore, avoid both an epistemological monism that affirms the existence of a methodological model that is common to all sciences and the thesis of a methodological abyss between the human and the natural sciences.

KEY-WORDS

hermeneutics; interpretation; science;

theory; observation 
O círculo da compreensão parece ser o núcleo racional que permanece depois de retirarmos todos os fatores irracionais da tese da distinção ou da posição especial das humanidades perante as ciências naturais. - Wolfgang Stegmüller ${ }^{1}$

A passagem em epígrafe evidencia a relevância epistemológica da velha noção de círculo hermenêutico. No interminável debate entre os defensores da unidade da ciência e os defensores de um dualismo metodológico segundo o qual as ciências humanas seriam irredutíveis às ciências naturais e à sua metodologia, um dos argumentos que estes últimos podem invocar consiste precisamente na centralidade da interpretação ao nível do estudo do ser humano e na relação de circularidade que ela estabelece entre o intérprete e o interpretandum. Todavia, não é evidente que o círculo hermenêutico possa decidir o desfecho do debate entre o monismo e o dualismo metodológico. Com efeito, têm sido desenvolvidos esforços no sentido daquilo a que se poderia chamar uma naturalização do círculo hermenêutico, ou seja, no sentido de conceber o trabalho hermenêutico à luz da metodologia das ciências naturais. De acordo com esta perspetiva, o círculo hermenêutico, longe de ser uma especificidade das ciências humanas, também se pode encontrar nas ciências naturais, sob a forma de um círculo entre teoria e observação.

O presente artigo procura esclarecer a relevância do círculo hermenêutico para a filosofia da ciência, partindo de uma clarificação da noção de círculo hermenêutico (1), após o que se mostrará em que medida a referida noção pode contribuir para uma demarcação entre ciências naturais e ciências humanas (2) e se apreciará as perspetivas que se abrem a uma filosofia hermenêutica das ciências naturais (3). O artigo terminará com uma avaliação crítica das tentativas de reduzir o círculo da interpretação aos métodos empíricos das ciências naturais (4). Antecipando a conclusão final, podemos dizer que existe, de facto, uma especificidade metodológica das ciências humanas perante as ciências naturais, mas também se defenderá que existem afinidades significativas entre o trabalho hermenêutico e a investigação científico-natural, pelo que se deverá evitar um dualismo metodológico radical.

1 STEGMÜLLER, 1988, p. 103. 


\section{A noção de círculo hermenêutico}

A seguinte passagem do filólogo alemão Friedrich Ast é frequentemente apresentada como a primeira formulação clara do círculo hermenêutico: "A lei fundamental de toda a compreensão e de todo o conhecimento é encontrar o espírito do todo a partir do singular e apreender o singular através do todo" (AST, 1808, p. 178). Na sequência desta passagem, Ast exemplifica a circularidade da interpretação com a interdependência existente entre a compreensão do espírito da Antiguidade (o todo) e a compreensão de cada autor antigo (o singular). As mesmas considerações aplicar-se-iam naturalmente à relação texto-frase e à relação autor-texto. A mesma consciência da circularidade da interpretação encontra-se em Schleiermacher (1977, p. 329): “do mesmo modo que o todo é compreendido a partir do singular, também o singular só se deixa compreender a partir do todo".

A noção de círculo hermenêutico ganhou uma nova dimensão na reflexão hermenêutica de Heidegger e de Gadamer; uma dimensão existencial. Com efeito, nestes dois representantes da hermenêutica alemã do séc. XX, o círculo hermenêutico já não se limita à tese da interdependência entre a interpretação das partes e a interpretação do todo, pois refere se sobretudo à relação circular entre a pré-compreensão do intérprete (incluindo a sua autocompreensão) e o interpretandum. De modo a demarcar-se da conceção meramente filológica do círculo hermenêutico, Heidegger, em Ser e Tempo, atribui-lhe um carácter ontológico, procurando, assim, chamar a atenção para o facto de o círculo hermenêutico descrever um traço constitutivo do Dasein enquanto ente que existe sob o modo da compreensão. Mais precisamente, Heidegger alega que a nossa experiência do mundo só é possível a partir do sentido que é projetado a partir da nossa rede de práticas e do nosso contexto histórico, permanecendo inelutavelmente condicionada pelo horizonte do intérprete. A compreensão obedece, segundo Heidegger, a uma estrutura de antecipação (Vor-Struktur), de acordo com a qual, longe de haver uma interpretação sem pressupostos, a interpretação assenta numa posse prévia (Vorhabe) ou num determinado contexto prático, numa visão prévia (Vorsicht) ou numa perspetiva específica e ainda numa conceção prévia (Vorgriff), no sentido em que a interpretação está associada a uma certa grelha conceptual (cf. HEIDEGGER, 1993, p. 150).

Importa assinalar duas consequências epistemológicas particularmente importantes da reinterpretação heideggeriana do círculo hermenêutico. Em primeiro lugar, Heidegger inverte a relação tradicional entre interpretação e compreensão. Em vez de conceber a compreensão como o momento culminante de um processo interpretativo bem sucedido, Heidegger vê na compreensão uma 
apreensão e projeção de possibilidades de ser e de agir que seriam exploradas pela interpretação: "A interpretação funda-se existencialmente na compreensão, não sendo esta que surge daquela. A interpretação não é a tomada de conhecimento do compreendido, mas a elaboração das possibilidades projetadas na compreensão" (HEIDEGGER, 1993, p. 148).

Em segundo lugar, e em conexão estreita com este primeiro ponto, Heidegger opõe-se quer ao subjetivismo, quer ao objetivismo hermenêutico. A interpretação não é subjetiva nem objetiva, mas sim projetiva, visto que consiste numa elaboração ou exploração de possibilidades. A sua prática interpretativa ilustra bem este ponto; nas suas interpretações de filósofos como Aristóteles ou Nietzsche, é muitas vezes difícil determinar onde acaba o pensamento do autor interpretado e onde começa o pensamento do próprio Heidegger. Dado que a interpretação permanece sempre condicionada pela pré-compreensão do intérprete, o processo interpretativo é interminável, razão pela qual Heidegger, em vez de aspirar à objetividade, se limita a alertar contra a interferência de "ideias ocasionais" e "conceitos populares", apelando simultaneamente a que se desenvolva a interpretação a partir das "próprias coisas" (HEIDEGGER, 1993, p. 153). É de registar a preocupação de Heidegger em evitar um anarquismo hermenêutico, mas a verdade é que ele não oferece um antídoto satisfatório contra tal perigo.

Ao contrário de Heidegger, que se desinteressou da reflexão hermenêutica no período subsequente a Ser e Tempo, o projeto filosófico de Gadamer apresenta-se explicitamente como um projeto hermenêutico, e é a Gadamer que se deve em grande parte a difusão do assim chamado movimento hermenêutico na filosofia contemporânea. Na sua obra, Gadamer acolhe premissas e intuições heideggerianas, tais como a ideia de que a compreensão não é um comportamento entre outros do ser humano, mas o seu próprio modo de ser, bem como a tese da estrutura de antecipação da compreensão, que assume na obra de Gadamer a forma de uma reabilitação epistemológica da noção de preconceito. Mais precisamente, Gadamer alega que o nosso acesso à realidade é necessariamente condicionado por um horizonte de compreensão ou um conjunto de conceções prévias que permitem a atribuição de sentido às coisas, à experiência. Os preconceitos não podem ser simplesmente erradicados, pois são condições de inteligibilidade; "são predisposições da nossa abertura ao mundo, condições que permitem que tenhamos experiências e que aquilo que encontramos nos diga algo" (GADAMER, 1993, p. 224).

À semelhança de Heidegger, Gadamer vai dar um lugar de destaque à noção de círculo hermenêutico, combinando a visão tradicional da relação circular 
entre a parte e o todo com o círculo heideggeriano entre a pré-compreensão do intérprete e o interpretandum. Estas duas dimensões do círculo hermenêutico sobrepõem-se de forma clara na seguinte passagem:

Quem quer compreender um texto executa sempre um projetar. A pessoa em questão antecipa um sentido para o todo mal um primeiro sentido se mostra no texto. E, por seu turno, este primeiro sentido mostra-se apenas porque já se lê o texto com a expectativa de um determinado sentido. É na elaboração de um tal projeto antecipador, constantemente revisto, é certo, a partir da penetração posterior no sentido, que consiste a compreensão do que lá está. (GADAMER, 1990, p. 271)

O reconhecimento de que não existe uma interpretação sem pressupostos ou imune à ação dos nossos preconceitos desemboca naturalmente numa crítica das noções de um sentido objetivo ou de um "sentido em si" (cf. GADAMER, 1990, p. 477). A interpretação constitui, assim, um "processo infinito", avançando à medida que "fontes de erro" são progressivamente afastadas e novas fontes de compreensão ou "relações imprevistas de sentido" vão surgindo (GADAMER, 1990, p. 303). Interpretar não é reconstituir na sua integridade um sentido preexistente à interpretação, mas recontextualizar o objeto da interpretação no horizonte do intérprete, razão pela qual Gadamer concebe a compreensão como uma "fusão de horizontes".

A noção de círculo hermenêutico recebe várias formulações no opus magnum de Gadamer, Verdade e Método. Particularmente relevante, a este respeito, é a tese de que "se compreende diferentemente, se se compreende efetivamente" (GADAMER, 1990, p. 302). Esta afirmação exprime o facto de a compreensão depender das projeções e antecipações de sentido efetuadas a partir do contexto do intérprete, o que significa que, longe de existir $a$ interpretação correta de um interpretandum, os resultados da interpretação variam consoante os diferentes horizontes de compreensão. Não se trata de uma defesa do relativismo, mas da ideia de que o conhecimento da realidade humana requer uma multiplicação de diferentes perspetivas. Outra formulação relevante do círculo hermenêutico, que explicita bem a sua dimensão existencial, já exposta por Heidegger, é a seguinte: "toda a compreensão é, no fundo, autocompreensão" (GADAMER, 1990, p. 265). Por último, Gadamer também apresenta o círculo hermenêutico 
como a tese de que "os preconceitos [Vorurteile] do indivíduo, mais do que os seus juízos [Urteile], constituem a realidade histórica do seu ser" (GADAMER, 1990, p. 281; cf. GADAMER 1993, p. 224). Deste modo, ele mantém-se fiel à conceção ontológica do círculo hermenêutico proposta por Heidegger.

À semelhança do autor de Ser e Tempo, também Gadamer se defronta com o problema do relativismo hermenêutico, mas oferece uma resposta mais elaborada. Podemos atribuir a Gadamer três estratégias de defesa contra o perigo da arbitrariedade interpretativa. Em primeiro lugar, ele alega que a pertença do intérprete e do interpretandum a uma tradição comum limita o perigo da aplicação de preconceitos inadequados ao objeto da interpretação: "A antecipação de sentido que dirige a nossa compreensão de um texto não é uma ação da subjetividade, mas determina-se com base na comunidade que nos liga à tradição" (GADAMER, 1990, p. 298). Esta primeira resposta ao problema do relativismo hermenêutico é, porém, insatisfatória. A distância temporal pode fazer que com que o intérprete, apesar de pertencer à mesma tradição do objeto da sua interpretação, aborde este último com preconceitos inadequados. Além disso, na comunicação intercultural não se pode apelar a uma tradição comum. Mas Gadamer tem uma segunda estratégia para combater o perigo do relativismo hermenêutico; o teste da coerência, ao abrigo do qual se pressupõe que a projeção de sentidos ou preconceitos inadequados a um texto, por exemplo, não permite um relato coerente do mesmo:

Que é que caracteriza a arbitrariedade das pré-conceções inadequadas a não ser o facto de se aniquilarem através do seu desenvolvimento? (GADAMER, 1990, p. 272)

A concordância de todos os pormenores com o todo é o respetivo critério da correção da compreensão. A ausência de tal concordância significa o fracasso da compreensão. (GADAMER, 1990, p. 296)

Warnke (1994, p. 86) atribui a Gadamer uma terceira linha de defesa contra o perigo do relativismo hermenêutico: a presunção da verdade do que é dito. Gadamer defende, de facto, que se deve presumir a verdade do texto, e podemos admitir que uma tal presunção pode estreitar o leque de interpretações admissíveis. 


\section{O círculo hermenêutico e a autonomia metodológica das ciências humanas}

Tal como foi desenvolvida por Heidegger e Gadamer, a noção de círculo hermenêutico conduz a uma crítica do objetivismo nas ciências humanas. No caso de Heidegger, não havendo uma interpretação sem pressupostos, a interpretação tem, como vimos, um carácter projetivo, e não objetivo. Para além disso, nas ciências humanas interpretam-se os entes a partir de um horizonte de compreensão constituído pela tradição cultural e pelas práticas sociais do intérprete, o que contrasta com a descontextualização dos entes que é promovida pela ciência natural. De forma análoga, Gadamer defendeu que as ciências humanas representam uma forma de conhecimento substancialmente diferente do ideal metódico da ciência moderna. $\mathrm{O}$ facto de Gadamer ter dedicado a primeira das três partes de Verdade e Método a uma análise da arte é, a este respeito, esclarecedor. A arte constitui um modelo para a reflexão epistemológica sobre as ciências humanas, porque ela é também uma forma de conhecimento, na medida em que revela aspetos da realidade que nos passam normalmente despercebidos; de forma análoga, as ciências humanas, as Geisteswissenchaften, oferecem-nos não um conhecimento objetivo, mas uma multiplicidade de perspetivas sobre a realidade, que constituem enquanto tal uma forma de conhecimento.

De modo a aprofundar as consequências da hermenêutica ao nível da epistemologia das ciências sociais e humanas, será útil fazer uma referência neste contexto a Charles Taylor, o qual pode ser legitimamente considerado o principal representante da conceção hermenêutica das ciências humanas no mundo anglo-saxónico ${ }^{2}$. Baseando-se num paralelismo entre a interpretação dos textos e a investigação da realidade social, Taylor opõe-se a uma conceção nomológica das ciências sociais orientada para a descoberta de relações causais. Em conformidade com a tradição hermenêutica, defende que o comportamento humano só pode ser estudado à luz do sentido de ações, práticas, instituições. A sua defesa da autonomia das ciências humanas baseia-se na noção de círculo hermenêutico, entendida nos seguintes termos:

O que estamos tentando estabelecer é uma certa leitura do texto ou expressões, e aquilo a que apelamos como fundamentos para tal leitura só podem ser outras leituras. (...) [E]stamos tentando estabelecer uma leitura para o texto no seu todo, e para tal apelamos a leituras das suas expressões parciais; e todavia,

2 A exposição que se segue baseia-se no famoso artigo de Taylor "Interpretation and the Sciences of Man" (reimpresso em TAYLOR, 1985b 
porque estamos a tratar de sentido, de fazer sentido, onde as expressões só fazem sentido ou não em relação com outras, as leituras de expressões parciais dependem das de outras, e em última instância do todo. (TAYLOR, 1985b, p. 18)

De acordo com Taylor, as ciências humanas envolvem necessariamente interpretação e um movimento circular de validação de interpretações com base noutras interpretações. Pelo contrário, e de acordo com uma conceção positivista das ciências empíricas, uma conceção que Taylor invoca sem criticar ${ }^{3}$, as ciências naturais poderiam saltar para fora do círculo da interpretação, apoiando-se em "dados brutos", entendidos como "dados cuja validade não pode ser questionada oferecendo outra interpretação ou leitura, dados cuja credibilidade não pode ser fundada ou minada por raciocínio posterior" (TAYLOR, 1985b, p. 19). De modo a reivindicar a autonomia epistemológica das ciências humanas perante as ciências naturais, Taylor alega que o estudo do comportamento humano não pode ser reduzido à procura de regularidades ou generalizações de tipo nomológico, uma vez que ele é caracterizado de forma essencial por ter sentido. Por seu turno, esta noção teria um carácter triplamente relacional; envolve de forma necessária uma relação não apenas a um sujeito e a um objeto, mas também, e de forma crucial, a um "campo de contrastes". O sentido que caracteriza o comportamento humano tem um carácter holístico:

As coisas só têm sentido num campo, i.e., em relação com os sentidos de outras coisas. Isto significa que não existe um elemento significativo isolado [unrelated]; e significa que mudanças nos outros sentidos no campo podem envolver mudanças no elemento dado. Os sentidos não podem ser identificados senão em relação com outros. (TAYLOR, 1985b, 22)

Esta defesa do carácter holístico do sentido já se encontrava claramente presente em Ser e Tempo, de Heidegger, especialmente na análise que ele faz da Zuhandenheit ou disponibilidade, o modo de ser que caracteriza os entes na

3 Taylor chega a afirmar que "o progresso da ciência natural conferiu grande credibilidade a esta epistemologia [do positivismo lógico], visto que ela pode ser plausivelmente reconstruída a partir deste modelo" (TAYLOR, 1985b, p. 20). O alvo polémico de Taylor em "Interpretation and the Sciences of Man" (artigo originalmente publicado em 1971) não é a conceção neopositivista da ciência natural, mas a aplicação do modelo da ciência natural às ciências humanas. 
nossa experiência quotidiana, os quais são tomados como utensílios que têm o sentido que têm em virtude do papel que desempenham nas nossas práticas e projetos. Ora, segundo Heidegger (1993, p. 68) "um utensílio não 'é', em rigor, nunca". Com efeito, o utensílio manifesta-se sempre no seio de uma totalidade instrumental (Zeugganzheit) e o seu sentido depende das relações que o articulam com outros utensílios e com os nossos fins. A tese da dependência do sentido perante um "campo de contrastes" e de sentidos previamente dados mina o ideal da objetividade na interpretação. A compreensão de um sentimento e comportamento de vergonha, para citar um dos exemplos de Taylor, requer a familiaridade com certos tipos de sentimentos e situações. A interpretação varia, por conseguinte, em função do repertório de sentimentos, situações e conceitos que um intérprete traz consigo. A seguinte passagem mostra bem em que medida o círculo hermenêutico induz uma rejeição do objetivismo epistemológico:

Assim, temos necessariamente um círculo hermenêutico. A nossa convicção de que o relato faz sentido depende da nossa leitura da ação e da situação. Mas estas leituras não podem ser explicadas ou justificadas a não ser por referência a outras leituras e à sua relação com o todo. Se um interlocutor não compreende este tipo de leitura, ou não a aceita como válida, a argumentação não pode prosseguir. Em última instância, uma boa explicação é aquela que torna o comportamento inteligível; mas então, para se apreciar uma boa explicação, tem que se estar de acordo sobre o que faz sentido; o que faz sentido é uma função das nossas leituras; e estas, por seu turno, são baseadas no tipo de sentido que se compreende. (TAYLOR, 1985b, p. 24)

As ciências humanas estão fundadas em "leituras de sentidos" e não em "dados brutos", razão pela qual elas requerem por parte do investigador uma certa capacidade de intuição, o que pode dar naturalmente origem a conflitos de intuições entre diferentes intérpretes ou investigadores (cf. TAYLOR, 1985b, p. 53). Na quarta parte deste artigo, serão analisadas tentativas de conciliação do círculo hermenêutico com os métodos empíricos das ciências naturais, com o intuito de exorcizar o espectro do relativismo hermenêutico. 


\section{A hermenêutica nas ciências naturais}

A tradição hermenêutica tem revelado um interesse muito maior pelas ciências humanas do que pelas ciências naturais. Tal tendência é compreensível, na medida em que o objeto da hermenêutica, a compreensão e a interpretação, parece dizer respeito sobretudo às ciências humanas. Apesar de figuras centrais da hermenêutica do séc. XX, como Heidegger e Gadamer, terem defendido a universalidade da hermenêutica, a verdade é que o movimento hermenêutico continuou a privilegiar as ciências humanas. A própria reflexão hermenêutica de Heidegger e de Gadamer aponta neste sentido. Heidegger defendeu que a compreensão, longe de ser um comportamento particular do Dasein, constitui o seu próprio modo de ser, mas não explorou as consequências de tal tomada de posição. A sua conceção da ciência deve ser analisada à luz da distinção entre dois modos de ser, Zuhandenheit e Vorhandenheit, que se podem traduzir por disponibilidade e subsistência. Heidegger alega que os entes se manifestam "imediata e regularmente" sob o modo da disponibilidade como utensílios, i.e., como entes que têm um sentido e um papel no âmbito das nossas práticas. A própria natureza manifesta-se como utensílio: "O bosque é parque florestal, a montanha é pedreira, o rio é energia hidráulica, o vento é vento nas velas" (HEIDEGGER, 1993, p. 70). Todavia, a investigação científico-natural e a ontologia tradicional privilegiam a subsistência em detrimento da disponibilidade, pois abstraem os entes do contexto prático em que eles se manifestam dotados de sentido. Mas há aqui uma nuance; a ciência descontextualiza o ente para, em seguida, o recontextualizar no quadro de teorias, modelos ou práticas científicas (cf. HEIDEGGER, 1993, pp. 362-3), ao passo que a ontologia tradicional se limita a descontextualizar ou desmundanizar os entes, que são compreendidos do ponto de vista da mera subsistência ${ }^{4}$. Gadamer, por seu turno, apesar de afirmar a universalidade da hermenêutica, mostrou-se curiosamente refém da conceção indutivista das ciências naturais em Verdade e Método ${ }^{5}$, o que ajuda a explicar a sua falta de interesse por uma filosofia hermenêutica das ciências naturais. Por último, o já citado Charles Taylor, no seu artigo de 1971 "Interpretation and the Sciences of Man", também é influenciado pela conceção positivista da ciência, quando admite, no domínio das ciências naturais a existência de "dados brutos" ou de uma base observacional neutra. Quando Taylor retoma a sua reflexão epistemológica sobre as ciências humanas alguns anos mais tarde no artigo

4Para uma análise mais detalhada deste ponto, cf. DREYFUS, 1995, pp. 202-8.

5 Weinsheimer (1985, p. 36) chama a atenção para esta tensão presente em Verdade e Método: "Tal como Heidegger, Gadamer considera a hermenêutica tão básica, tão intimamente implicada no mundo da vida, que é universal: ela compreende as ciências naturais como um caso especial (...). Todavia, ao mesmo tempo o intuito polémico de Verdade e Método decorre da crença de Gadamer de que as ciências naturais ainda se afirmam como uma alternativa independente, e portanto como uma ameaça para as ciências humanas." 
"Understanding in Human Science", ele constata a existência de uma tendência para considerar as ciências naturais tão hermenêuticas como as ciências humanas, mas recusa-se a associar-se a tal tendência, alegando que a tarefa das ciências naturais é "dar uma visão do mundo tal como ele é independentemente dos sentidos que ele possa ter para os sujeitos humanos" (TAYLOR, 1980, p. 31).

Este desinteresse de figuras centrais da hermenêutica do séc. XX perante as ciências naturais pode ser facilmente revisto à luz do desenvolvimento de uma filosofia da ciência pós-positivista. Popper, Kuhn e outros defensores da tese da impregnação teórica da observação apresentaram objeções de peso contra a tese indutivista tradicional segundo a qual a ciência se fundamenta em observações e só de forma lenta e gradual ascende a teorias. Segundo Popper, o acesso à realidade é mediado, nas ciências naturais, por expetativas e conjeturas; segundo Kuhn, a ciência normal evolui ao abrigo de um paradigma que funciona como uma grelha interpretativa que guia a investigação científica, indicando princípios teóricos fundamentais, modelos ontológicos e heurísticos, valores e realizações exemplares. Entendido como matriz disciplinar, a noção kuhniana de paradigma assemelha-se à noção hermenêutica de horizonte de compreensão ${ }^{6}$.

Mas em que medida pode a hermenêutica contribuir para a filosofia das ciências naturais? No domínio da filosofia da ciência, uma das principais diferenças entre a filosofia analítica e a tradição filosófica continental consiste na especial sensibilidade desta última à dimensão social, cultural e histórica do conhecimento. No caso da hermenêutica, esta sensibilidade histórica exprime-se numa valorização do contexto prático e do horizonte de sentido em que as ciências se enraízam ${ }^{7}$. De acordo com Heelan, um autor empenhado no desenvolvimento de uma filosofia hermenêutica das ciências naturais, a hermenêutica deve tratar a ciência como "uma forma de cultura humana constituída pela investigação e busca de sentido" (HEELAN, 1997, p. 288). Seguindo a herança de Husserl e Heidegger, mais precisamente, da fenomenologia husserliana do mundo-da-vida, enquanto solo onde se enraízam as idealizações científicas, e da reflexão heideggeriana do ser-no-mundo, Heelan propõe um programa de investigação orientado para a análise do campo pré-científico onde as ciências se edificam, um campo caracterizado pela "historicidade, visão englobante [circumspection], facticidade e temporalidade". Subjacente a esta orientação de pesquisa encontra-se a defesa da "prioridade da cultura sobre a teoria, ou de fins humanos sobre o conhecimento teórico" (HEELAN, 1997, p. 288).

6Heelan (1997, p. 278) considera a noção kuhniana de paradigma como uma instância particular da noção hermenêutica de "tradição de interpretação".

7 De acordo com Crease (1994, p. 262), uma filosofia da ciência inspirada pela hermenêutica baseia-se em três ideias fundamentais: a prioridade do sentido sobre a dimensão técnica da ciência, o primado do prático sobre o teórico e a prioridade da situação sobre a formalização abstrata. 


\section{O problema da naturalização do círculo hermenêutico}

Habermas, na sua obra Erkenntnis und Interesse, distinguiu entre ciências naturais e ciências humanas (Geisteswissenchaften), afirmando que as primeiras se caracterizam pelo método hipotético-dedutivo, ao passo que as segundas se baseiam em métodos hermenêuticos. Føllesdal (1994, p. 233) criticou esta distinção, alegando que "o método hermenêutico é o método hipotético-dedutivo aplicado a materiais com sentido (textos, obras de arte, ações, etc.)." Com efeito, existem importantes similaridades entre os dois métodos. O hipotético-dedutivo pode decompor-se em dois momentos: a formulação de hipóteses e a subsequente dedução de consequências observacionais a partir delas, culminando numa confrontação entre hipótese e experiência. Um ponto particularmente relevante deste método é o facto de ele envolver, como Føllesdal salienta, uma justificação das nossas crenças a partir de baixo, i.e., a partir das consequências deduzidas, e não a partir de cima, das hipóteses ou premissas do raciocínio científico. Visto a esta luz, o método hipotético-dedutivo assemelha-se ao círculo hermenêutico, tal como descrito, por exemplo, por Gadamer. A interpretação envolve, como vimos, projeções ou antecipações de sentido a partir dos pressupostos ou preconceitos do intérprete, as quais se assemelham às hipóteses do método hipotético-dedutivo, ao passo que a revisão das projeções de sentido no decurso do processo interpretativo se assemelha ao teste das hipóteses através da sua confrontação com a experiência. Gadamer alertou corretamente para o papel que a presunção de coerência desempenha na interpretação; distinguimos entre preconceitos adequados e inadequados ao interpretandum com base no princípio segundo o qual as antecipações de sentido incorretas se revelam incapazes de fornecer um relato coerente do objeto da interpretação; de forma análoga, hipóteses incorretas acarretam consequências incongruentes com os dados da experiência. O método hipotético-dedutivo permite ainda acomodar a tese hermenêutica do pluralismo das interpretações, visto que também nas ciências empíricas existe uma subdeterminação da teoria pelos dados; o mesmo conjunto de dados pode ser explicado por diferentes hipóteses, como foi reconhecido desde Simplício até Quine. À luz destas considerações, Føllesdal parece ter alguma razão na sua tentativa de redução do círculo hermenêutico ao método hipotético-dedutivo.

Seguindo uma linha de argumentação semelhante à de Føllesdal, encontra-se Michael Martin, o qual, num artigo sobre Charles Taylor, acusou este último de ter uma conceção ingénua das ciências naturais enquanto formas de investigação e de conhecimento supostamente baseadas numa "base observacional neutra" 
(MARTIN, 1994, p. 266). Martin alega que, uma vez aceite a assim chamada tese da impregnação teórica da observação, uma tese central e amplamente difundida da filosofia da ciência pós-positivista, a circularidade que Taylor vê em ato nas ciências humanas deveria estender-se também às ciências naturais, agora sob a forma de uma relação circular entre a teoria e os dados observacionais por ela impregnados ${ }^{8}$. Não havendo "dados brutos" nas ciências naturais, cai a barreira que Taylor afirmava existir entre ciências humanas e ciências naturais. Mas isto não teria as consequências anti-objetivistas que Taylor sugere:

Assim que se toma em consideração o carácter teoricamente impregnado [theory-laden] da observação nas ciências naturais, não se pode fazer a distinção que Taylor alega existir entre a validação de hipóteses na hermenêutica e o teste de hipóteses na ciência natural. Além disso, uma vez que o carácter teoricamente impregnado da observação nas ciências naturais não torna o teste objetivo impossível, há razão para supor que a validação objetiva possa não ser impossível também em interpretações textuais. (MARTIN, 1994, p. 266)

Martin tem, de facto, o mérito de mostrar que a tese da impregnação teórica da observação não tem consequências tão desastrosas como se poderia à primeira vista pensar. Da argumentação aduzida por Martin a este respeito há três pontos que merecem ser destacados. Em primeiro lugar, Martin alega que o facto de a linguagem observacional conter categorias teóricas não impede o surgimento de enunciados observacionais que contradizem premissas teóricas. Trata-se de uma observação correta, mas cujo alcance é limitado. Por vezes, e tal como Feyerabend mostrou em Against the Method, os factos que permitem refutar uma teoria só podem ser descobertos a partir de outra teoria9 ${ }^{9}$ Martin reconhece implicitamente este ponto ao admitir que "dados (evidence) negativos em relação a uma teoria não são frequentemente reconhecidos pelos cientistas por causa dos seus compromissos teóricos prévios" (MARTIN, 1994, p. 267).

$8 \mathrm{O}$ capítulo X do famoso livro de Kuhn The Structure of Scientific Revolutions oferece uma expressão clássica desta tese da impregnação teórica da observação.

9Feyerabend (1993, pp. 54-76) dava o exemplo de Galileu e da experiência do lançamento de um objeto pesado do cimo de uma torre. O facto de o objeto cair junto à torre provava, segundo a física medieval, que a Terra está imóvel. A refutação desta interpretação natural da experiência só seria possível a partir de uma teoria do movimento que incluísse o princípio de inércia, bem como o princípio segundo o qual o movimento partilhado não é operativo. 
Porém, tais casos seriam limitados; além disso, é possível, em princípio, detetar e corrigir eventuais contaminações teóricas da observação. Estabelecendo um paralelo com a interpretação dos textos, podemos dizer que também a este nível se pode distinguir entre categorias e premissas interpretativas. Além disso, e como o critério da coerência proposto por Gadamer o demonstra, é possível, sem sair do círculo hermenêutico, detetar preconceitos ou pressuposições inadequadas ao texto. O próprio confronto com outras interpretações contribui para detetar os preconceitos operantes nas nossas interpretações. De forma análoga, Feyerabend, na sua defesa do pluralismo teórico na ciência, i.e., da necessidade de um cientista explorar em simultâneo diferentes teorias rivais, chama a atenção para o facto de que "os preconceitos são encontrados por contraste, não por análise" (FEYERABEND, 1993, p. 22). Esta é uma afirmação que corresponde plenamente ao espírito da hermenêutica gadameriana, a qual valoriza fortemente a abertura à alteridade do outro, por ser normalmente através do confronto com outras perspetivas que tomamos consciência dos nossos preconceitos.

Na sua defesa da objetividade perante o desafio lançado pela tese da impregnação teórica da observação, Martin também salienta, em segundo lugar, que, para se testar empiricamente uma teoria, é frequentemente possível recorrer a observações independentes da teoria que está a ser testada. Este é outro ponto importante, que também pode ser utilizado ao nível do círculo hermenêutico tal como é tradicionalmente entendido no domínio das ciências humanas. Nas palavras de Martin: "Uma leitura de uma passagem particular, embora baseada nalguma interpretação, pode não estar baseada na interpretação particular que está a ser validada por esta leitura" (MARTIN, 1994, p. 269).

Em terceiro lugar, Martin chama a atenção para aquelas situações em que diferentes dados de diferentes proveniências apontam para propriedades diferentes de uma mesma entidade ou processo ${ }^{10}$. Nestes casos, a existência da entidade ou do processo em questão fica suficientemente estabelecida e a observação, mesmo impregnada teoricamente, desempenha bem a sua função de controlo das teorias. Do ponto de vista hermenêutico, também é muitas vezes possível validar uma interpretação através de uma convergência de diferentes fontes de informação.

Em todo o caso, há boas razões para duvidar de uma redução do círculo hermenêutico aos procedimentos metódicos das ciências empíricas. Há, com efeito, duas diferenças significativas entre o círculo hermenêutico e o processo de formação e teste de hipóteses na ciência. A primeira diz respeito aos pontos de partida da investigação empírica e da interpretação da ação humana.

10 O exemplo dado por Martin é o de um médico que por diferentes vias recolhe provas de diferentes sintomas de uma mesma doença. 
As hipóteses científicas podem ter múltiplas origens; podem ser sugeridas pela observação, mas também podem resultar de rasgos imaginativos, especulações metafísicas ou mesmo de crenças religiosas. Popper, um destacado representante do método hipotético-dedutivo, defendeu inclusivamente uma conceção muito liberal do processo de formação de hipóteses, de acordo com a qual não existiria um conjunto de regras ou princípios que governasse tal processo; regras metodológicas só entrariam propriamente em jogo com o teste empírico das hipóteses (cf. POPPER, 1993, pp. 31-2). Pelo contrário, na interpretação de entidades ou acontecimentos com sentido, o ponto de partida é constituído por pressuposições de racionalidade. Esta expressão é normalmente associada a discussões sobre a interpretação e a explicação da ação humana na filosofia anglo-saxónica, mas a ideia que exprime está também claramente presente na hermenêutica de Gadamer, em particular num princípio hermenêutico que ele designou como "antecipação da perfeição" (Vorgriff der Vollkommenheit). Tal princípio, que é apresentado como uma consequência do círculo hermenêutico, consiste, em primeiro lugar, na presunção da coerência do interpretandum; "só é compreensível aquilo que apresenta efetivamente uma unidade perfeita (vollkommene) de sentido" (GADAMER, 1990, p. 299). Em segundo lugar, o princípio estabelece também a pressuposição da verdade do que é dito: "Não se pressupõe apenas uma unidade imanente de sentido que guia o leitor; a compreensão do leitor é também permanentemente conduzida por expectativas transcendentes de sentido que emergem da relação com a verdade do que é visado" (GADAMER, 1990, p. 299). Este último ponto entronca com um leitmotiv da hermenêutica gadameriana, a saber, que a interpretação do sentido é indissociável de uma busca da verdade sobre o tema em questão. De acordo com Gadamer, a compreensão (Verstehen) é um processo de entendimento (Verständigung) que aspira a um acordo (Einverständnis) sobre um determinado assunto ${ }^{11}$. Sob este ponto de vista, a compreensão não pode ser entendida à luz do modelo da empatia, como sucedia na hermenêutica romântica e na escola histórica alemã do séc. XIX. Contra uma "hermenêutica da reconstrução", orientada para a reconstituição de pensamentos e vivências de outrem, Gadamer propõe uma "hermenêutica da integração" (cf. GADAMER, 1990, 169-174), segundo a qual a compreensão assume a forma de uma fusão de horizontes e envolve a discussão da verdade do que é dito. Sob este ponto de vista, o círculo hermenêutico parte de pressuposições de racionalidade, o que marca a sua especificidade relativamente à investigação científico-natural.

Um dos autores que mais enfatizou o papel de pressuposições de racionalidade ao nível da interpretação do discurso e da ação humana foi Donald Davidson, um filósofo analítico que partilha com a tradição hermenêutica a tese de

11 A este respeito, cf. GADAMER, 1990, pp. 183, 297 e 387. 
que a explicação da ação humana envolve métodos interpretativos claramente distintos da metodologia das ciências naturais. De acordo com o seu famoso Princípio de Caridade, um intérprete deve necessariamente presumir que o falante tem um conjunto de crenças largamente verdadeiras e é em geral coerente. A pressuposição da verdade do que é dito seria legitimada, por um lado, por uma teoria verocondicional do significado, segundo a qual o significado de uma frase é dado pelas suas condições de verdade e, por outro, por uma conceção holística do domínio psicológico, de acordo com a qual o conteúdo de um estado mental como um desejo ou crença é parcialmente constituído pelas suas relações com outros estado mentais, o que esvazia de sentido a noção de um falante com um sistema de crenças largamente falsas. Crenças falsas e incoerências só são inteligíveis contra um pano de fundo de crenças verdadeiras e de coerência. Deste modo, apesar de a investigação dos fenómenos físicos e o estudo dos fenómenos mentais serem governados por normas, são-no por normas substancialmente diferentes; tal como diz Davidson, na interpretação de uma pessoa, "impomos necessariamente condições de coerência, racionalidade e consistência", as quais "não têm eco na teoria física" (DAVIDSON, 1984, p. 231). Interpretar é racionalizar, e racionalizamos o comportamento alheio com base no nosso sistema de crenças e de valores; citando de novo Davidson, ao interpretarmos um agente, "procuraremos uma teoria que o revele como consistente, um crente em verdades e um amante do bem (tudo pelos nossos padrões, desnecessário seria dizê-lo)" (Davidson, 1980, p. 222).

É possível objetar que o facto de as hipóteses envolvidas nos procedimentos interpretativos envolverem pressuposições de racionalidade não implica uma diferença significativa entre métodos interpretativos e métodos empíricos; o próprio Føllesdal (1994, p. 242) reconhece que a interpretação é movida por "hipóteses de racionalidade". Todavia, ele subestima o impacto desta diferença. As hipóteses científicas são construções teóricas que, apesar de terem origem num determinado contexto social ou histórico, autonomizam-se de tal contexto, ao passo que as pressuposições de racionalidade remetem de forma essencial para o contexto prático do intérprete; para um mundo da vida ou, para utilizar uma expressão cara a Wittgenstein, para uma forma de vida. Isto faz da interpretação uma capacidade prática que requer a existência de afinidades significativas ao nível de práticas sociais ou tradições culturais entre o intérprete e aqueles que interpreta. $\mathrm{Na}$ ausência de tais afinidades a compreensão pode falhar, e este é um problema que não tem correspondência no domínio das ciências naturais. A interpretação não é apenas um exercício da racionalidade teórica, mas também da racionalidade prática.

Advogados da naturalização do círculo hermenêutico podem, todavia, contestar que a explicação da ação envolva pressuposições de racionalidade. 
É o caso de Mantzavinos, que distingue claramente entre explicação da ação e reconstrução racional da ação: "Uma coisa é apreender uma ação nomologicamente e assim explicá-la; outra é reconstruir uma ação racionalmente ex post facto" (MANTZAVINOS, 2005, p. 101). Note-se que segundo este autor seria também possível apreender nomologicamente conexões de sentido (cf. MANTZAVINOS, 2005, p. 126). Como abaixo veremos, há boas razões para adotar uma atitude cética perante a existência de leis do comportamento humano, ceticismo este que é particularmente justificado quando tais leis são formuladas com recurso a noções intencionais. Mas no presente contexto devemos concentrar-nos na tese de que a reconstrução racional de uma ação não constitui uma explicação genuína. A racionalização ou reconstrução racional de uma ação pode, efeticamente, ser arbitrária, e sob este ponto de vista tal noção deve ser sempre encarada de forma crítica. Todavia, há uma distinção relevante entre boas e más racionalizações da ação humana. As boas distinguem-se, por exemplo, pela capacidade de oferecer um relato coerente e abrangente do comportamento do agente, de se basearem em valores e normas que estruturam o contexto social do agente e de apelarem a princípios psicológicos plausíveis. Para além disso, uma racionalização da ação pode ser posteriormente testada. Assim sendo, uma reconstrução racional da ação, não sendo uma explicação científica, não deixa de ser uma explicação potencialmente satisfatória.

Esta primeira diferença entre o círculo hermenêutico e o método hipotético-dedutivo nas ciências naturais faz-se acompanhar, do lado do objeto, por uma outra diferença fundamental. No domínio das ciências humanas, e ao contrário do que sucede nas ciências naturais, o próprio objeto da investigação move-se num domínio normativo e regula-se por interpretações. A tese da existência de uma "hermenêutica dupla" nas ciências humanas ajuda-nos a compreender esta segunda diferença entre métodos interpretativos e métodos científico-naturais. Nas ciências naturais, o cientista acede à realidade empírica a partir de uma determinada tradição científica e um certo quadro conceptual. Nas ciências humanas, porém, a situação epistemológica complica-se, pois aqui não é apenas o sujeito da investigação, mas também o seu objeto, i.e., o agente cujo comportamento ou ação se pretende explicar, que se caracteriza por uma grelha interpretativa. Nas palavras de Giddens:

...a sociologia lida com um universo que está desde logo constituído por quadros de significado pelos próprios atores sociais e reinterpreta-os nos seus esquemas teóricos, mediando a linguagem técnica e comum. Esta hermenêutica dupla é de considerável complexidade, já que a conexão não se faz num único sentido; existe um 
contínuo "deslizar" dos conceitos construídos em sociologia através do qual são apropriados por aqueles cujo comportamento visavam - tendo sido criados para tal analisar e, assim, tendem a tornar-se aspetos fundamentais desse comportamento. (GIDDENS, 1996, pp. 184-5)

O domínio das ciências humanas não só é estudado a partir de princípios normativos de racionalidade, como além disso é constituído por normas e racionalidade; não só é investigado a partir de um quadro interpretativo, como além disso se regula por quadros interpretativos. Tal como disse Taylor (1985a, p. 45-76), os seres humanos são "self-interpreting animals", seres capazes de se definirem a si próprios de múltiplos modos, moldando com estas interpretações o próprio objeto estudo das ciências humanas, que se caracteriza, assim, por uma instabilidade que não tem paralelo nas ciências naturais. Esta é uma das razões pelas quais explicações de tipo nomológico têm um alcance limitado nas ciências sociais e humanas. Com efeito, como ser que se define a si próprio, o ser humano é capaz de inovar ao nível do pensamento, criando novos conceitos e novas interpretações, o que se reflete ao nível da ação, com inovações ao nível das práticas e comportamentos. Deste modo, as regularidades do comportamento humano, mesmo quando são estáveis, não devem ser confundidas com regularidades naturais, dada a instabilidade e imprevisibilidade próprias de um "animal que se interpreta a si próprio". Muitas generalizações nas ciências humanas são seguramente úteis e podem ter um poder explicativo relevante, mas terão de ser complementadas por métodos interpretativos que apreendam as razões da ação ou as crenças e valores que dão sentido ao comportamento humano. Tais métodos, além de terem o mérito de poder explicar as exceções às generalizações usadas nas ciências humanas, iluminam uma importante dimensão da ação humana que é eclipsada por uma conceção da ciência apenas orientada para a descoberta de regularidades e correlações entre variáveis.

Termino esta reflexão sobre o significado epistemológico do círculo hermenêutico com uma nota wittgensteiniana. Em vez de se procurar uma definição rígida do conceito de ciência em termos de condições necessárias e suficientes, devemos, antes, conceber a ciência como uma família de práticas mais ou menos aparentadas entre si. Assim sendo, devemos evitar quer um unitarismo epistemológico que defende a existência de um modelo metodológico comum a todas a ciências, quer a tese de um abismo metodológico entre ciências humanas e ciências naturais. Tal como a análise do círculo hermenêutico aqui proposta procurou mostrar, os procedimentos hermenêuticos revelam afinidades importantes com a metodologia das ciências empíricas, não sendo, todavia, redutíveis a estas. 
AST, F. Grundlinien der Grammatik, Hermeneutik und Kritik. Landshut: Jos. Thomann, 1808.

CREASE, R. 1997. "Hermeneutics and the natural sciences". Man and World 30, 259-70.

DAVIDSON, D. Essays on Actions and Events. Oxford: Clarendon Press, 1980.

DREYFUS, H. 1995, Being-in-the-World, Cambridge, MA,The MIT Press.

FEYERABEND, P. Against Method. London/New York: Verso, 1993.

FØLLESDAL, D. "The Status of Rationality Assumptions in Interpretation and in the Explanation of Action". Dialectica 36, 1982, 301-316.

(1979). "Hermeneutics and the hypotheticodeductive method'. In: MARTIN, M. e MCINTYRE, L. (eds.). Readings in the Philosophy of Social Science. Cambridge, MA: The MIT Press, 1994.

GADAMER, H.-G. (1960). Wahrheit und Methode: Grundzüge einer philosophischen Hermeneutik. Tübingen: J.C.B. Mohr, 1990. . (1986). Wahrheit und Methode. Ergänzungen

- Register. Tübingen: J. C. B. Mohr, 1993.

GIDDENS, A. Novas Regras do Método Sociológico. Gradiva: Lisboa, 1996.

HEELAN, P. 1997. "Why a hermeneutical philosophy of the natural sciences?". Man and World 30, 271-298.

HEIDEGGER, M. (1927). Sein und Zeit. Tübingen: Max Niemeyer Verlag, 1993.

KUHN, T. The Structure of Scientific Revolutions. Chicago: The University of Chicago Press, 1970.
POPPER, K. A Lógica da Pesquisa Científica. São Paulo: Cultrix, 1993.

MANTZAVINOS, C. Naturalistic Hermeneutics. Cambridge: Cambridge University Press, 2005.

MARTIN, M. "Taylor on Interpretation and the Sciences of Man". In: MARTIN, M. e MCINTYRE, L. (eds.). Readings in the Philosophy of Social Science. Cambridge, MA: The MIT Press, 1994.

SCHLEIERMACHER, F. Hermeneutik und Kritik. Frankfurt/M: Suhrkamp, 1977.

STEGMÜLLER, W. “Walthervon der Vogelweide's Lyric of Dream-Love and Quasar 3-C 273”. In: CONNOLLY, J. e KEUTNER, T. Hermeneutics versus Science? Three German Views. Notre Dame, IN: University of Notre Dame Press, 1988.

TAYLOR, C. "Understanding in Human Science". Review of Metaphysics 34, 25-38.

Human Agency and Language. Cambridge: Cambridge University Press, 1985(a).

. Philosophy and the Human Sciences. Cambridge: Cambridge University Press, 1985(b).

WARNKE, G. Gadamer. Hermeneutics, Tradition and Reason. Cambridge: Polity Press, 1994.

WEINSHEIMER, J. Gadamer's Hermeneutics. New Haven/London: Yale University Press, 1985.

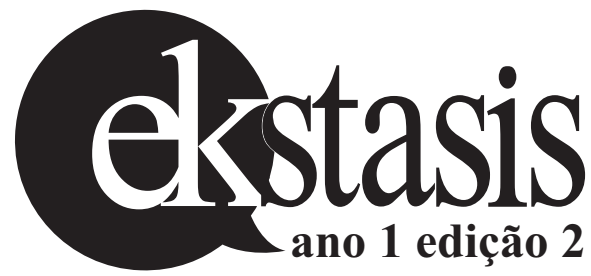

